\section{DIARY}

\section{OCTOBER}

34th Annual Meeting of the Society of Craniofacial Genetics in conjunction with the International Congress of Human Genetics

Date: 11 October 2011

Location: Montreal, Canada

www.craniofacialgenetics.org

Quicksleeper 4 digital controlled local anaesthetic system - Hands On Course Date: 14 October 2011 (Glasgow) Date: 28 October 2011 (Birmingham) Telephone: 01380734990

Email:info@generalmedical.co.uk www.generalmedical.co.uk

\section{BDTA Dental Showcase}

Date: 20-22 October 2011

Venue: NEC, Birmingham

www.dentalshowcase.com

Bruxism Awareness Week 2011

Date: 24-30 October 2011

Tel: 01142500176 (for free information pack)

Email:info@s4sdental.com

www.s4sdental.com

\section{NOVEMBER}

PEDOQUEST, 33rd ISPPD Conference, Mangalore

Date: 4-6 November 2011

Location: Mangalore, India

Email: registration@33isppd.com

www.33isppd.com/index.html

BACD 'Something to Smile

About' conference

Date: 11-12 November 2011

Venue: Hilton London Metropole Hotel

Tel: 02082418526

Email: suzy@bacd.com

CDA Workshop

'The role of oral health personnel in cases of abuse'

Date: 23-26 November 2011

Location: Barbados

Email: veastmond@caribsurf.com

Dental Protection Premier

Symposium 2011

Date: 26 November 2011

Venue: Imperial College, London

Tel: 02073992914

Email: events@dentalprotection.org

\title{
CLINICAL SIMULATION CENTRE OPENED
}

In July Dr Susan Gregory opened the newly refurbished Plymouth Regional Initiative in Dental Education (PRIDE) dental clinical simulation centre in Derriford Hospital in Plymouth.

The centre has 12 phantom heads, is used for continuing professional development (CPD) for all members of the dental team and hosts over 40 courses per annum.

The refurbishment project was supported by NHS Education South West and was managed by Heidi Mills, a dental nurse who runs the centre.

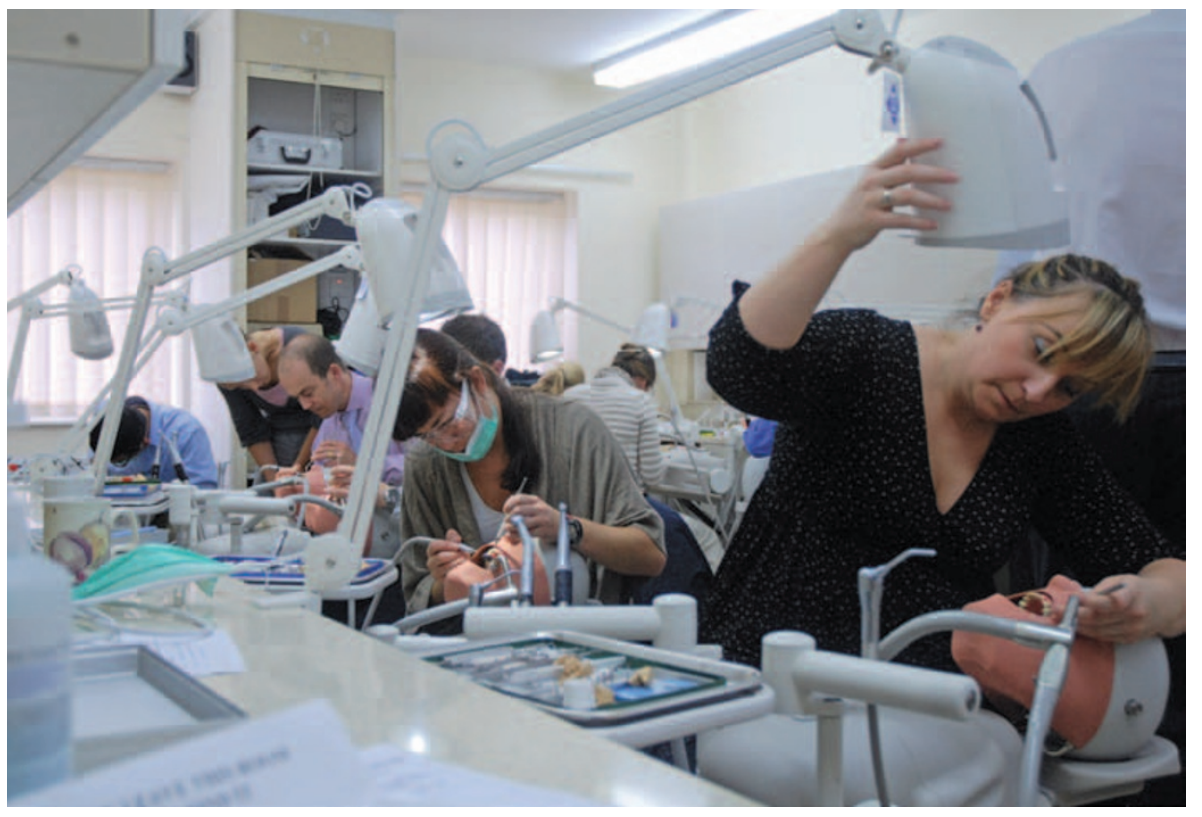

